\title{
Dermoscopic Features of Chondrodermatitis Nodularis Chronica Helicis: A Case Series
}

\author{
Daniel Morgado-Carrasco ${ }^{1}$, Xavier Fustà-Novell ${ }^{1}$, Sebastian Podlipnik ${ }^{1}$, Lara Ferrandiz ${ }^{1}$
}

1 Department of Dermatology, Hospital Clínic de Barcelona, Universitat de Barcelona, Spain

Key words: chondrodermatitis nodularis chronica helicis, chondrodermatitis, ear, squamous cell carcinoma, dermoscopy

Citation: Morgado-Carrasco D, Fustà-Novell X, Podlipnik S, Ferrandiz L. Dermoscopic features of chondrodermatitis nodularis chronica helicis: a case series. Dermatol Pract Concept. 2019;9(1):52-53. DOI: https://doi.org/10.5826/dpc.0901a12

Published: January 31, 2019

Copyright: (2019 Morgado-Carrasco et al. This is an open-access article distributed under the terms of the Creative Commons Attribution License, which permits unrestricted use, distribution, and reproduction in any medium, provided the original author and source are credited.

Funding: None.

Competing interests: The authors have no conflicts of interest to disclose.

Authorship: All authors have contributed significantly to this publication.

Corresponding author: Lara Ferrandiz, MD, Department of Dermatology, Hospital Clínic de Barcelona, Villarroel 170, 08029 Barcelona, Spain.Email: lferrandiz@e-derma.org

\section{Introduction}

Chondrodermatitis nodularis chronica helicis $(\mathrm{CNCH})$ is a benign inflammatory disorder. It is characterized by a 4- to 5-mm large, painful, solitary nodule or papule on the helix. The pathogenesis of $\mathrm{CNCH}$ remains elusive. Differential diagnosis includes cutaneous malignancies such as squamous cell carcinoma (SCC) [1]. Diagnosis is mostly made clinically, but histopathological examination is recommended. Dermoscopy can help in the diagnosis of many tumoral or inflammatory skin disorders. To date, dermoscopic features of $\mathrm{CNCH}$ have not been defined. We sought to describe the dermoscopic findings in a series of patients with $\mathrm{CNCH}$.

\section{Case Presentation}

Five patients ( 2 men and 3 women) with biopsy-proven, untreated $\mathrm{CNCH}$ were included. Median age was 72 years (range, 46-83 years). Clinical and dermoscopic photographs were taken before the biopsy, using a Canon Powershot G16 camera with a DermLite foto epiluminescence system (3Gen, Inc, San Juan Capistrano, CA). These images were evaluated independently by 4 dermatologists, 3 with 3 years of expe- rience in dermoscopy and 1 with more than 15 years and considered an expert in the field. The process was not blind, as the final diagnosis $(\mathrm{CNCH})$ was known by the evaluators. The final dermoscopic descriptions were achieved through a consensus among the evaluators.

Five lesions were analyzed. Two were located on the right helix, 1 on the left helix, and 2 on the left anthelix. Clinically, all the lesions were erythematous hyperkeratotic papules (Figures 1A and 2A), one of them eroded (Figure 2D). On dermoscopy, the lesions were round; 4 lesions presented with structureless white areas and irregular, ill-defined vessels at the periphery; the fifth had multiple erosions (Figure 2D). At the center, 1 lesion had keratin and a yellow-brown flat crust (Figure 1B), 1 had a central erosion (Figure 1C), 2 had a raised yellowish keratotic crust (Figure $2 \mathrm{~B}$ and 2D), and 1 had a structureless yellowish area (Figure 2C). None of the dermatologists found any useful clue to differentiating $\mathrm{CNCH}$ from SCC by dermoscopy.

\section{Conclusions}

Differentiating CNCH from SCC is crucial, as clinical presentation can be very similar, and the ear is considered a high-risk 

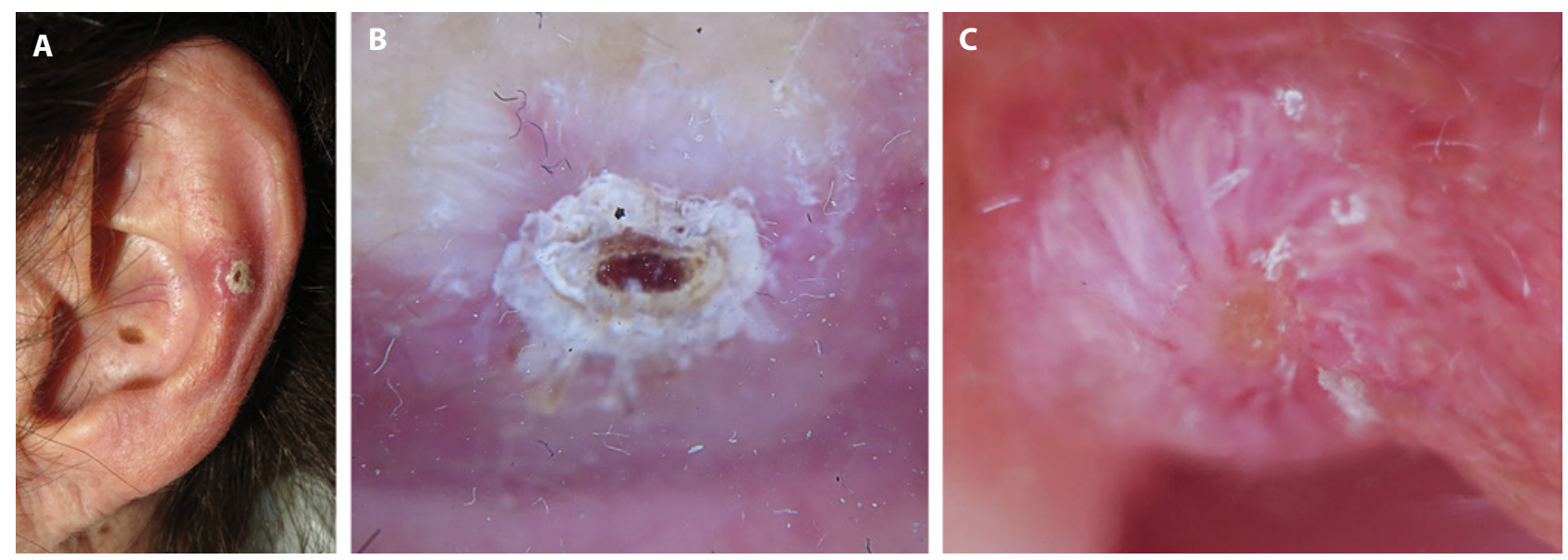

Figure 1. Chondrodermatitis nodularis chronica helicis. (A) Clinical image: Erythematous hyperkeratotic papule on the left anthelix. (B,C) Dermoscopy: Structureless white areas and irregular, ill-defined vessels at the periphery. At the center, keratin and a yellow-brown flat crust (B), an erosion (C). [Copyright: @2019 Morgado-Carrasco et al.]
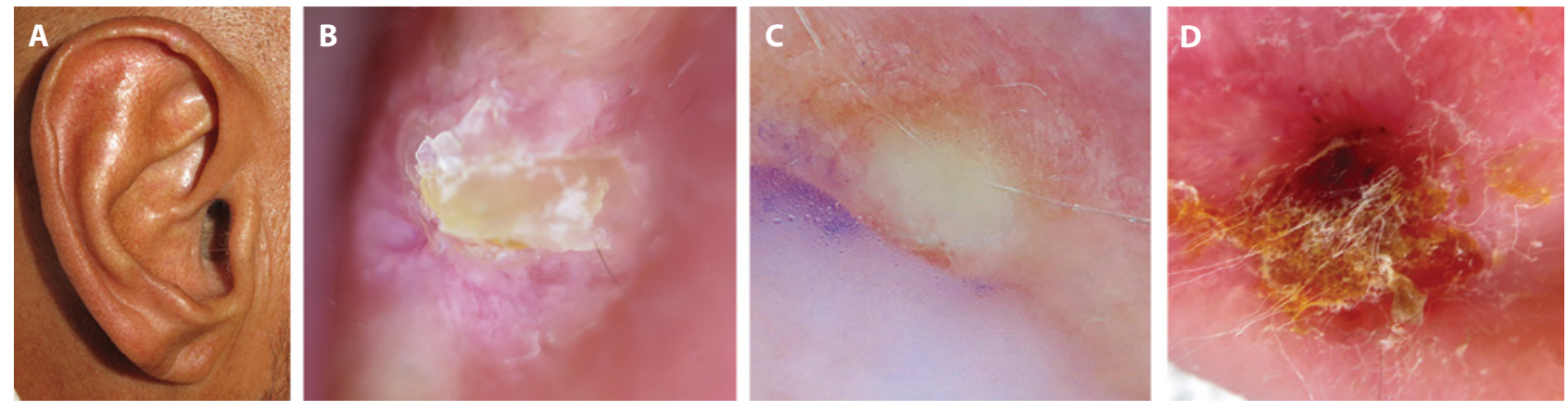

Figure 2. Chondrodermatitis nodularis chronica helicis. (A) Clinical image: Erythematous hyperkeratotic papule on the right helix. (B-D) Dermoscopy: Structureless white areas and irregular, ill-defined vessels at the periphery. A raised yellowish keratotic crust at the center (B). Structureless yellowish area (C). Yellowish crusts and erosions (D). [Copyright: (02019 Morgado-Carrasco et al.]

location in SCC. It has been suggested that pain can be an important sign when diagnosing $\mathrm{CNCH}[1]$. However, pain can also be associated with SCC and it may be a powerful patient-reported warning signal for invasive SCCs. Moreover, painful SCCs can be associated with increased mortality, at least in organ transplant recipients. Dermoscopic features of well-differentiated SCC include yellow scales, structureless white areas, and a central mass of keratin or yellow keratotic follicular plugs surrounded by a white rim and irregular vessels [2]. These dermoscopic characteristics are practically the same as those described for $\mathrm{CNCH}$ in this report.

The main limitation of our study is the small number of lesions analyzed.

$\mathrm{CNCH}$ presented dermoscopically with central keratin or an erosion surrounded by structureless white areas and ill-defined vessels. These characteristics did not allow the differentiation of $\mathrm{CNCH}$ from SCC. Histopathological examination is recommended. $\mathrm{CNCH}$ belongs to the group of dermatoses in which the diagnosis demands an integrated clinico-dermoscopic and histological diagnostic approach.

\section{References}

1. Wagner G, Liefeith J, Sachse MM. Clinical appearance, differential diagnoses and therapeutical options of chondrodermatitis nodularis chronica helicis Winkler. J Dtsch Dermatol Ges. 2011;9(4):287-291.

2. Rosendahl C, Cameron A, Argenziano G, Zalaudek I, Tschandl P, Kittler H. Dermoscopy of squamous cell carcinoma and keratoacanthoma. Arch Dermatol. 2012;148(12):1386-1392. 